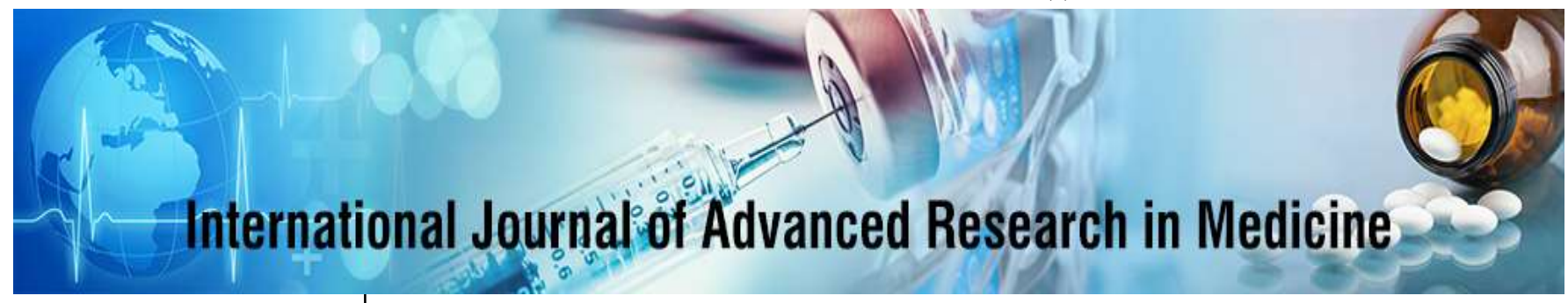

E-ISSN: 2706-9575

P-ISSN: 2706-9567

IJARM 2021; 3(1): 407-410

Received: 29-01-2021

Accepted: 18-03-2021

Dr. Ellabathini Hima Bindu Assistant Professor,

Department of Pharmacology,

Osmania Medical College,

Hyderabad, Telangana, India
Corresponding Author: Dr. Ellabathini Hima Bindu Assistant Professor, Department of Pharmacology, Osmania Medical College, Hyderabad, Telangana, India

\title{
Awareness, approach and application of pharmacovigilance: A questionnaire-based analysis in a tertiary care centre
}

\section{Dr. Ellabathini Hima Bindu}

DOI: https://doi.org/10.22271/27069567.2021.v3.i1g.172

\section{Abstract}

Background: Adverse Drug Reactions (ADRs) are a public health issue that health providers need to address. Health practitioners play a significant part in improving the healthcare environment, which is a cornerstone of the pharmacovigilance programme.

Objective: To evaluate the awareness of pharmacovigilance expertise and practice among doctors in our college.

Methods: A questionnaire with 15 pharmacovigilance questions has been created. Convenient and purposive sampling techniques were used, which contacted and invited doctors at our institute to engage in this research. This required participants to be recruited who were willing to provide pharmacovigilance information at our hospital.

Results: It was found that doctors had excellent knowledge of the basic principles for pharmacovigilance in $20 \%$, good in $38 \%$, average in $14 \%$ and poor in $28 \%$. $28 \%$ of people had low pharmacovigilance awareness, $7 \%$ of whom had no practical knowledge of pharmacovigilance, and had zero results in class A. The response was outstanding for 26 percent, good for 26 percent, average for 16 percent and poor for 32 percent. Out of 32 percent of respondents with inadequate expertise, 20 percent were unable to provide any productive advice or viewpoint on the pharmacovigilance improvement scheme and scored zero in Class D.

Conclusion: This research concluded that awareness and practice on various aspects of pharmacovigilance among residents was increased after proper sensitization. Better perception may also eliminate misunderstandings, obstacles and barriers to a better healthcare system's use of pharmacovigilance.

Keywords: Pharmacovigilance, ADR, PvPI, Healthcare workers

\section{Introduction}

Drugs are an important aid and benefit in the therapeutic treatment of any disease. On the one hand, drugs cure, prevent, manage or diagnose diseases, but on the other hand they are also susceptible to harm in the way of Adverse Drug Reactions (ADRs) which are some of the greatest inconveniences of them ${ }^{[1]}$.

ADR is described by the World Health Organisation (WHO) as "a reaction to a medication that is noxious, unintended and typically takes place at doses used in humans to prophylaxis, diagnosis, treat a disease or to change physiological activity ${ }^{[2]}$.

Higher ADR rates is an issue with public health that all parties, irrespective of the practice setting, need to be conscious of. Drugs have been found to contribute to $5 \%$ of all hospital admissions and 10\%-20\% of the patients in hospital develop ADRs with consecutive increased healthcare costs ${ }^{[3]}$.

The identification or spontaneous notification of ADR to guarantee patient safety includes pharmacovigilance, a critical study in the field of medicines. Pharmacovigilance helps to enhance health treatment and drug protection, and to better determine the benefit, danger, efficacy and risk of drugs. Medical practitioners are the backbone of and hence play an important part of the pharmacovigilance programme ${ }^{[4]}$.

Active involvement in the identification and monitoring of ADRs by reporters is essential for pharmacovigilance. At present, though, ADR monitoring appears to be not part of the healthcare provider practice which is a significant downside for the system ${ }^{[5]}$.

Pharmacovigilance practices in India, like many other developed countries, face a host of problems such as underreporting ADRs and preserving reporting culture ${ }^{[6]}$. 
The value of healthcare practitioners tracking and monitoring ADRs contributes to the recurrence of preventable drug-related morbidity and death. As noted in previous research, most hospital admissions ADRs are attributed to common drugs and are predominantly preventable ${ }^{[7]}$.

Awareness and experience will play an important role in ensuring that the pharmacovigilance software is effectively introduced ${ }^{[8]}$. The effectiveness in pharmacovigilance activities relies significantly on the involvement of health practitioners in their day-to-day care, medication and surveillance roles. They are unavoidable in the pharmacovigilance field because their views and attitude to ADRs add to the aggregation of ADR results. Based on such results, regulatory bodies can decide on drug use that poses a threat to patient safety ${ }^{[9]}$.

Reporting ADRs is optional and non-compulsory to healthcare workers; under these terms, knowledge of reporting of ADRs should also be measured, and should any remedial steps be taken with regard to campaigns or training programs for the same should be identified at the required level ${ }^{[10]}$.

\section{Materials and Methods}

Type of Study: Observational and Prospective study. A questionnaire with 15 pharmacovigilance questions has been created. Convenient and purposive sampling techniques were used, which contacted and invited doctors at our institute to engage in this research. This required participants to be recruited who were willing to provide pharmacovigilance information at our hospital.

The research was explained to the participants and the questionnaire was then filled based on their individual awareness. They were not permitted to consult the group mates on any issue for their input. The participants were confined to one sitting to fill out the questionnaire without any time constraints. Both completed surveys have been collected, compiled and analysed.

\section{Questionnaire}

1. Are you aware of Pharmacovigilance?

2. Are you aware of the Pharmacovigilance national program?

3. Do you understand pharmacovigilance's relevance to the term?

4. Do you know the Pharmacovigilance aims?

5. Do you know where an adverse drug reaction could be reported?

6. Are you aware of a vast array of strategies to reduce adverse drug reactions?

7. Do you know how to respond if there is an adverse drug reaction/drug adverse effect?

8. Did you intervene to rectify by necessary interventions after you have detected an adverse drug reaction?

9. Do you foresee Pharmacovigilance to conflict with medicine's knowledge of the doctor?

10. Do you anticipate Pharmacovigilance to interfere in right patients with knowledge of the right medication for the right indication?

11. Do you foresee some factual advantage in the Pharmacovigilance management of patients??
12. Should the method of pharmacovigilance be mentioned in hospitals?

13. Do you endorse an integrated approach for pharmacovigilance training and education in the medical and general public?

14. Do you think it would be helpful for the institution to have an independent body to monitor adverse drug reactions?

15. Can the necessary guidelines be made to increase monitoring and responsible use of drugs in the areas of organisation, policy, laws and resources for safe use of drugs?

Each question was based on two option: "yes" or "no" in the questionnaire. Questions in the questionnaire were further split into four classes for exposure appraisal in multiple pharmacovigilance definition areas.

First class was classified as class 'A' containing six questions, i.e. questions $1,3,4,6,7$ and 8 concerning basic information and interventions in the field of pharmacovigilance. Group 'B' covered problems relating to the pharmacovigilance reporting method, i.e. query no. 2 and 5. Questions about the potential advantages of pharmacovigilance (i.e. questions 9,10 and 11) were included in class 'C.' Similarly, class D has been classified by a series of questions about how the enhanced pharmacovigilance method, e.g. questions 12, 13, 14, and 15 , should be constructively implemented.

Each "Yes" answer was provided with one score, and each "No" had zero and for the entire category of questions a composite score was determined. A scale was used to assess participants' knowledge of pharmacovigilance.

Table 1: Grading scale to determine the awareness of residents about pharmacovigilance

\begin{tabular}{|c|c|c|c|c|c|}
\hline \multirow[b]{2}{*}{ Class } & \multirow{2}{*}{$\begin{array}{c}\text { Total no. } \\
\text { of } \\
\text { questions }\end{array}$} & \multicolumn{4}{|c|}{ Grading Scale } \\
\hline & & Excellent & Good & Average & Poor \\
\hline A & 6 & 6 & 5,4 & 3 & $<2$ \\
\hline B & 2 & 2 & - & 1 & 0 \\
\hline $\mathrm{C}$ & 3 & 3 & 2 & 1 & 0 \\
\hline $\mathrm{D}$ & 4 & 4 & 3 & 2 & $<1$ \\
\hline $\begin{array}{l}\text { Total } \\
\text { score in } \\
\text { each } \\
\text { category }\end{array}$ & 15 & 15 & $10 / 9$ & 7 & $3 / 2 / 1 / 0$ \\
\hline
\end{tabular}

Statistical Analysis: Statistical analysis was done using SPSS 21 software and the data was presented in the form of tables.

\section{Results}

The findings were compiled for each doctor

Table 2: Distribution based on gender and junior and senior resident doctors

\begin{tabular}{|c|c|}
\hline Gender & Total Number of participants $\mathbf{n = 1 0 0}$ \\
\hline Male & 31 \\
\hline Female & 19 \\
\hline Total & 50 \\
\hline
\end{tabular}

Male were around $62 \%$ and females were $38 \%$. 
Table 3: Score earned by residents in different classes of questions

\begin{tabular}{|c|c|c|c|c|}
\hline $\begin{array}{c}\text { Score } \\
\text { Earned }\end{array}$ & $\begin{array}{c}\text { Class A } \\
(\mathbf{N = 5 0})\end{array}$ & $\begin{array}{c}\text { Class B } \\
(\mathbf{N = 5 0}\end{array}$ & $\begin{array}{c}\text { Class C } \\
(\mathbf{N}=\mathbf{5 0})\end{array}$ & $\begin{array}{c}\text { Class D } \\
(\mathbf{N}=\mathbf{5 0})\end{array}$ \\
\hline 0 & $3(6.00 \%)$ & $22(44.00 \%)$ & $12(24.00 \%)$ & $10(20.00 \%)$ \\
\hline 1 & $6(12.00 \%)$ & $13(26.00 \%)$ & $10(20.00 \%)$ & $6(12.00 \%)$ \\
\hline 2 & $5(10.00 \%)$ & $15(30.00 \%)$ & $13(26.00 \%)$ & $8(16.00 \%)$ \\
\hline 3 & $7(14.00 \%)$ & - & $15(30.00 \%)$ & $13(26.00 \%)$ \\
\hline 4 & $13(26.00 \%)$ & - & - & $13(26.00 \%)$ \\
\hline 5 & $6(12.00 \%)$ & - & - & - \\
\hline 6 & $10(20.00 \%)$ & - & - & - \\
\hline
\end{tabular}

It was found that doctors had excellent knowledge of the basic principles for pharmacovigilance in $20 \%$, good in $38 \%$, average in $14 \%$ and poor in $28 \%$. $28 \%$ of people had low pharmacovigilance awareness, $7 \%$ of whom had no practical knowledge of pharmacovigilance, and had zero results in class $\mathrm{A}$.

The awareness about the pharmacovigilance reporting method was excellent in $30 \%$ of the doctors, average in $26 \%$ and poor in $44 \%$ of class B questionnaire.

Of the residents, 30 percent were excellent, 26 percent were good, 20 percent were average and 24 percent were poor in awareness of the potential benefits of class $\mathrm{C}$ pharmacovigilance.

The response was outstanding for 26 percent, good for 26 percent, average for 16 percent and poor for 32 percent. Out of 32 percent of respondents with inadequate expertise, 20 percent were unable to provide any productive advice or viewpoint on the pharmacovigilance improvement scheme and scored zero in Class D.

Table 4: Mean score of the response obtained in different classes

\begin{tabular}{|c|c|c|}
\hline \multicolumn{3}{|c|}{ Class A } \\
\hline Average score (Mean \pm SD) & SEM & p value \\
\hline $3.157 \pm 1.88$ & 0.24 & $<0.0001-\mathrm{ES}$ \\
\hline \multicolumn{3}{|c|}{ Class B } \\
\hline Average score (Mean \pm SD) & SEM & $\mathrm{p}$ value \\
\hline $0.87 \pm 0.85$ & 0.11 & $<0.0001-\mathrm{ES}$ \\
\hline \multicolumn{3}{|c|}{ Class $\mathrm{C}$} \\
\hline Average score (Mean \pm SD) & SEM & $\mathrm{p}$ value \\
\hline $1.58 \pm 1.15$ & 0.15 & $<0.0001-\mathrm{ES}$ \\
\hline \multicolumn{3}{|c|}{ Class D } \\
\hline Average score (Mean \pm SD) & SEM & $\mathrm{p}$ value \\
\hline $2.28 \pm 1.48$ & 0.19 & $<0.0001-\mathrm{ES}$ \\
\hline
\end{tabular}

\section{Discussion}

This study reveals that most doctors know about pharmacovigilance but still reporting is low. Pharmacovigilance Programme of India (PvPI) perception among doctors was marginally lower and contributed to a pharmacovigilance constructivism.

Almost all the doctors participated in the study seemed to know the concept of pharmacovigilance, but most of the participants could not define the word "pharmacovigilance." Most participants had the ability to explain ADRs and medication errors and could also provide some details, including examples of ADRs in their area of practice. The reporting instruments and the reporting process were not known to most people. This was apparent due to the great difference in how much ADRs are detected and the amount of ADR official records that had been received in the hospital at that time. This was like most retrospective research done previously ${ }^{[11,12]}$.
However, the understanding and experience of this was on the lower part as found in our research, which can be due to a high workload, lack of resources, misunderstanding of the pharmacovigilance system, lack of input and tools. ADRs were found relevant in terms of clinical aspects by most doctors, and they thought that it should be documented in order to avoid potential tragedies caused by drugs ${ }^{[13]}$.

However, we understood that due to their intense workload, they experience extra work during their daily practice. However, they decided to report. This was a favourable reaction to potential pharmacovigilance practices in the hospital.

Under reporting is a grave problem, and reasons of underreporting are not just the lack of time but of so many clinical routine activities. Easy monitoring patterns, data, free number assistance, financial rewards, the creation of additional ADR centres, and contact between medical practitioners and pharmacovigilance centres will resolve this underreporting ${ }^{[14,15]}$.

The strength of our research is that; in this study, we measured awareness and experience before and after academic interventions. In addition, this research has demonstrated that regular awareness-raising and training will enhance understanding and practice in various areas of pharmacovigilance. The drawback of our analysis is that the participants' reactions may have been affected by the bias of reporting. Moreover, the survey was performed only on doctor in that hospital on the basis that the information presented is compatible with all healthcare providers in that hospital, which leads to a further restriction.

\section{Conclusion}

This research concluded that awareness and practice on various aspects of pharmacovigilance among residents was increased after proper sensitization. Better perception may also eliminate misunderstandings, obstacles and barriers to a better healthcare system' $s$ use of pharmacovigilance. To properly understand this system, various medical practitioners need a large-scale understanding of pharmacovigilance. Moreover, a particular attention on medical education pharmacovigilance and its integration into medical procedures must be put on the rational application of medication. Among prospective doctors would be expected to eliminate adverse events or other drug-related issues to a minimum.

\section{References}

1. Ayalew MB, Megersa TN, Mengistu YT. Drug-related problems in medical wards of Tikur Anbessa specialized hospital, Ethiopia. J Res Pharm Pract. 2015;4(4):216-21. 
2. Importance of Pharmacovigilance Safety Monitoring of medicinal products [Internet]. United Kingdom: World Health Organization 2002. [cited 3 February 2021]. Available from: https://apps.who.int/medicinedocs/pdf/s4893e/s4893e.p df 3 .

3. Aronson JK. Adverse drug reactions- no farewell to harms. Br J Clin Pharmacol 2007;63(2):131-5.

4. Pirmohammed M, James S, Meakin S, Green C, Park BK. Adverse drug reactions as a cause of admission to the hospital: prospective analysis of 18820 patients. $\mathrm{Br}$ Med J. 2004;329:15-9.

5. Ratan JL, Mangala L, Sukirti D. A study on adverse drug reactions in a tertiary care hospital of northeast India. Alex J Med 2017;53:151-6 6.

6. Bouvy JC, De Bruin ML, Koopmanschap MA. Epidemiology of adverse drug reactions in Europe: a review of recent observational studies. Drug Saf. 2015;8:437-53.

7. Jayanthi CR, Renuka M, Panchaksharimath P. An observational Study to analyze the Adverse drug Reactions among the Elderly at A Tertiary Care Hospital. Biomed Pharmacol J. 2017;10(1):345-52.

8. Bates DW, Spell N, Cullen DJ, Burdick E, Laird N, Petersen LA. The costs of adverse drug events in hospitalized patients. Adverse Drug Events Prevention Study Group. JAMA. 1997;277:307-11.

9. Pharmacovigilance Programme of India (PvPI) Updates: Performance Report 2018-19 [Internet]. Ghaziabad: Indian Pharmacopoeia Commission; 2019 [cited 2 February 2021]. Available from: https://ipc.gov.in/mandates/pvpi/pvpiupdates/8category-en/646-annual-performance-report. 10.

10. Kalaiselvan V, Prakash J, Singh GN. Pharmacovigilance programme of India. Arch Pharm Pract 2012;3:229-32.

11. Vallano A, Cereza G, Pedros C, Agustí A, Danés I, Aguilera $\mathrm{C}$ et al. Obstacles and solutions for spontaneous reporting of adverse drug reactions in the hospital. Br J Clin Pharmacol 2005;60(6):653-8.

12. A Framework for Assessing the Economic Value of Pharmacovigilance in Low- and Middle-Income Countries - Springer. [cited 2021 Jan 22]; Available from: http://link.springer.com/article/10.1007/s40264014-0143-1/fulltext.html 13.

13. Hussain MM, Girhepunje K, Pal R, Siddiqua SS. Incidence of Adverse Drug Reactions in a Tertiary Care Hospital: A Systematic Review and Meta-Analysis of Prospective Studies. Scholars Res Library. 2010;2(3):358-67.

14. Khan FA, Nizamuddin S, Najmul H, Mishra H. A prospective study on prevalence of adverse drug reactions due to antibiotics usage in otolaryngology department of a tertiary care hospital in North India. Int J Basic Clin Pharmacol 2013;2:548-53.

15. Ramesh M, Pandit J, Parthasarathi G. Adverse drug reactions in a south Indian hospital - Their severity and cost involved. Pharmacoepidemiol Drug Saf. 2003;12:687-92. 